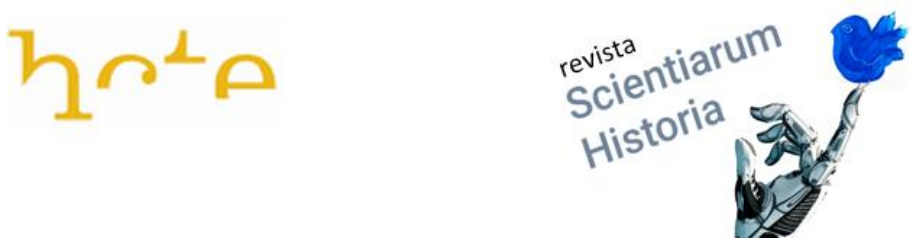 \\ Caraibing the wacky Pindorama: vegan anthropophagous without an anus manifest
}

\section{Caraibando a Pindorama Desvairada: antropófago vegano sem ânus manifesto}

\author{
Bruno da Silva Mussa Cury, Claudia Santos Turco, Eduardo Nazareth Paiva, \\ Gabriela de Assis, Marcos Fialho de Carvalho, Maria Cristina de Oliveira \\ Cardoso, Mario Afonso da Silveira Barbosa, Nahya Paola Souza, Thiago José \\ Bezerra Cavalcanti
}

Programa de Pós-graduação em História das Ciências e das Técnicas e Epistemologia, Universidade Federal do Rio de Janeiro

\begin{abstract}
mussacury@gmail.com, claudia.turco@hcte.ufrj.br, edu@hcte.ufrj.br, gabrielaassis@hcte.ufrj.br, fialho@nce.ufrj.br, mcristinaocardoso@gmail.com, mario_a@nce.ufrj.br, paolaufrj@gmail.com, tcavalcanti@hcte.ufrj.br
\end{abstract}

Recebido: 27/04/2021 Aceito: 29/04/2021 Publicado: 04/05/2021

DOI: 10.51919/revista_sh.v1i0.319

\begin{abstract}
A hundred years without anus. But what about us with this? Could the Oswaldian aphorisms of the Manifesto Antropófago (Anthropophagous Manifest) be upgradable and localizable a century later? The aphoristic language of Oswald de Andrade, Friedrich Nietzsche and Luis Enrique Morales is our first inspiration to face the challenge of answering these questions.
\end{abstract}

Keywords. Manifests. Anthropophagy. Aphorisms.

Resumo. Cem anos sem ânus. Mas que temos nós com isso? Os aforismos Oswaldianos do Manifesto Antropófago seriam atualizáveis e localizáveis um século depois? A linguagem aforística de Oswald de Andrade, de Friedrich Nietzsche e de Luis Enrique Morales é a nossa primeira inspiração para enfrentar o desafio de responder a estas perguntas.

Palavras-chave. Manifestos. Antropofagia. Aforismos. 


\section{Introdução}

O que temos nós com isso?

Encarnando uma alma selvagem, experimentaremos o desafio de manifestar algumas historicidades envolvidas nas ciências, nas técnicas e na epistemologia a partir de uma linguagem aforística. Não será algo nem trivial, nem clássico. A poética será o nosso esteio. "A poesia existe no fatos", disse Oswald de Andrade no primeiro aforismo do seu MANIFESTO DA POESIA PAU-BRASIL, de 1924 (ANDRADE, 2011,p.21), em comunhão com o princípio de sua contra-existência autodeclarada selvagem: traidor dos discursos que garantem a realidade subjugada ao numinoso (essa, talvez, a mais conhecida história de dormir já contada através de gerações pelas gargantas coloniais). Em Manifesto Pau-Brasil, Oswald inaugura - na América Latina - o desvio à afirmação total do Ocidente, tal como o fizera Nietszche em 1883 (NIETZSCHE, 2002) na Alemanha com seu homem total, seu escárnio à totalidade do homem (branco/europeu): os fatos e o numinoso são justaposições do racional e do irracional (CARUZO, 2021). Tal como nos evocam as premissas autóctones de pindorama, é a partir dos fatos embebidos pelas muitas teias do inefável - esses mesmos fatos orgânicos já abocanhados, deglutidos, digeridos e (re) vomitados pela essência da Terra (brasilis) - que a realidade se Mani-Festa. Regojizam-se os homens, mais ainda as mulheres. A selvageria como princípio, a afirmação da não civilidade, a negação dos fatos estéreis; dos acordos corridos em melanina (preta) sobre papel timbrado (branco); e a poética incompletude utópica do Manifesto Antropófago o faz ingrediente de protesto-banquete ainda hoje. Bastam ver os conclames por uma descolonização das bocas, ouvidos e mãos dos sujeitos subalternizados ocidente adentro, transpondo as fronteiras entre Natureza e Cultura. Enfim, de acordo com Viveiros de Castro (2002, p.348), a distinção clássica entre Natureza e Cultura não pode ser utilizada para descrever dimensões ou domínios internos a cosmologias não-ocidentais sem passar antes por uma crítica etnológica rigorosa. Alexandre Nodari nos chama a atenção: Resta apenas saber se vamos seguir a lição do Manifesto, isto é, se vamos aprender a "Acreditar nos sinais". (NODARI, 2011, p.483).

Nesse tempo histórico que vivemos, marcados pela pandemia de COVID-19, viabilizada pelos processos de globalização, assistimos pendengas de toda ordem, por exemplo, aquelas entre as vacinas e os tratamentos precoces ou imediatos. Neste imbróglio os selvagens se veem como grupos de risco. As tecnociências nesses tempos de pandemia se fazem onipresentes, tanto nas crises quanto nas soluções, propondo e atuando através das mais diversas tecnologias: inativação do vírus cultivado e multiplicado nas culturas de células, vetor viral não replicante, replicação de sequências de RNA, quebra de proteínas, etc. São laboratórios, fábricas e agenciamentos para todo lado. Lugares de controvérsias que provocam divisões, inclusive na própria ciência que agora se apresenta ora como a ciência aberta ora como a ciência das patentes. Sobre esse marco histórico pandêmico, Airton Krenak nos alerta: "E temos agora esse vírus, um organismo do planeta, respondendo a esse pensamento doentio dos humanos com um ataque à forma de vida insustentável que adotamos por livre escolha, essa fantástica liberdade que todos adoram reivindicar, mas ninguém se pergunta qual o seu preço". (KRENAK, 2020, p. 3). Alguns autores considerados clássicos como, como Álvaro Vieira Pinto (2005, p.40), também já nos alertava: "A falta de visão histórica, notada na expressão dos 
contemporâneos, supõe a ausência do dia seguinte, a sacralização do presente imobilizado, o desejo de esconjurar as transformações perturbadoras do estado existente. Neste sentido, há realmente uma variante original de mentalidade ingênua da maioria dos atuais teóricos da tecnologia. Não conseguindo entravar um progresso impetuoso operado em todos os terrenos, tendo por correlato o inevitável esclarecimento da consequência das massas, adotam outra estratégia. Em vez de negar o futuro, ou de ignorá-lo, domesticamno de antemão, descrevendo-o com excesso de maravilhosos detalhes, todos produtos da imaginação, no visível intento de apresentá-lo segundo lhe convém."

Somos humanos. E a Ciência também. A Ciência produzida por pessoas com corpos, situadas no tempo, no espaço, na Cultura e na Sociedade, se empenhando por credibilidade e autoridade, mas nunca pura (SHAPIN, 2013). Oswald de Andrade, nosso autor de referência maior neste texto, também tinha seus desarranjos. Oswald, como a mosca de Raul Seixas, caiu na sopa: antes, as cabeças, uma a uma, dos eguns das caravelas foram arrotadas pelos retratos oswaldianos do índio mítico, romântico e lustroso - seus Peris e suas Cecis de inquestionável fertilidade. Mais ainda, os pratos preparados pelas mães criadeiras de tetas cheias em tons de negras disfarçáveis, herança colorista com suas cabeças minúsculas e pés/mãos enormes de trabalho, trabalho e trabalho. Foram chamados para encherem as barrigas numa festa em sua honra e homenagem, é verdade, mas obrigados a comer o que foi escolhido pela sinhá; o gordo cardápio todo em inglês mas sempre com algumas boas regadas de dendê para disfarçar o molho branco. Como escreveram os compositores Aldir Blanc e João Bosco em sua música "Dois Mil e Índio": “Anjo do Inferno: Brasil, Índio do ano 2000!".

Enfim, nesses tempos em que se fala tanto expressões como "novo normal" coincide com uma espécie de era de giros e viradas. Carlos Eduardo Freitas escreve a respeito deste momento epistemológico: Sobre a expressão "era das viradas", ela refere-se aos múltiplos movimentos de deslocamento e realimento epistemológico e ontológico, vividos não somente pela sociologia, mas por toda a constelação das ciências humanas, dentre as quais, podemos mencionar os movimentos de "giro linguístico", "giro hermenêutico", "giro cultural", "giro pragmático", "giro ontológico", "giro pós-colonial e decolonial", "giro pós-social", dentre outros. (FREITAS, 2018, p.27).

Numa tentativa de escapar deste fogo no mato em que nos encontramos, buscamos inspiração no rodopio. Segundo SIMAS \& RUFINO (2018, p. 35): "O rodopio configurase como o giro que desloca os eixos referências, fazendo com que aqueles princípios que comumente são compreendidos como objetos a serem investigados e que por uma série de relações/poder são mantidos sobre uma espécie de regulação discursiva sejam credibilizados como potências emergentes e transgressivas. Falamos de amarrações versadas, balaios, pontos riscados que enigmatizam e anunciam outros princípios explicativos de mundo, orientados por outras lógicas de saber que revelam experiências que emergem como outros referenciais".

A devoração da antropofagia Oswaldiana será o nosso rodopio. Da maneira como foi servido, ao localizarmos o Manifesto Antropófago neste mundo pandêmico, fica a necessidade de se limpar os cantos da boca com esse molho mal disfarçado - nem engolido, tampouco saboreado pela selvageria criativa. 100 anos depois, sem ânus, advogamos por um banquete com indígenas de cocar, terra e celular; pretos, pretas e marrons com cabeças enormes e mãos habilidosas, blacks e tranças armadas 
materialidades de conhecimentos e intelectualidades acumuladas ao longo de séculos. Se Oswald pariu seu Manifesto pela perpetuação dos princípios plenos da vida, agora pensamos ser o momento de entoá-lo pelo som dos caxixis também em favor das potências da morte: a poesia resiste aos fatos! Queremos comer, queremos dar de comer: quem escolhe o cardápio agora? Oswald caiu na bandeja e o comemos. E o que temos nós, mestres e doutores das tecnociências, com tudo isso? Quem somos nós? Que trabalho é este?

Este trabalho foi elaborado por aqueles que frequentaram a disciplina "Introdução aos Pensamentos Antropofágicos na Tecnociência", ministrada no histórico primeiro semestre acadêmico do ano de 2020, oferecida no Programa de Pós-graduação em História das Ciências e das Técnicas e Epistemologia da Universidade Federal do Rio de Janeiro (HCTE-UFRJ). O livro-texto adotado no curso foi "Antropofagia - palimpsesto selvagem", de Ana Beatriz Azevedo (AZEVEDO, 2016).

Ao explorar a linguagem aforística, este trabalho traz um pouco de uma tentativa de expressão do que foi este ano acadêmico vivido em tantos "fragmentos" que acabou não cabendo nele próprio, ou seja, o ano acadêmico de 2020 acabará em 2021. Ana Beatriz Sampaio Soares de Azevedo (AZEVEDO, 2012, p.79), atriz, musicista e pesquisadora brasileira, define a palavra fragmento como uma indicação de que o texto seria uma parcela integrante de algo maior, "uma parte de um todo". Neste sentido, para nós aqui, um aforismo será visto como um fragmento. Parafrasearemos os aforismos do Manifesto Antropófago de Oswald de Andrade (ANDRADE, 1928) em uma tentativa de trazer nossa leitura de um pensamento antropofágico na tecnociência. (PAIVA, 2019). 

O aforismo pode também ser visto como um lugar cheio de fórmulas e frases que são citadas continuamente, mas de maneira isolada e assim se tornam pedaços deslocados de alguma identidade filosófica (STEGMAIER, 2010, p. 248).

\section{Nossos aforismos, noves fora, mundo afora}

A seguir, faremos uma lista de aforismos inspirados e parafraseados a partir dos cinquenta e um aforismos do Manifesto Antropófago (ANDRADE, 1928).

Estamos gravando. Todos concordam?

Só a morte nos une. Socialmente. Economicamente. Filosoficamente. Única Lei do mundo da lua. Honeymoon. Expressão mascarada de todos os individualismos, de todos os coletivismos. De todas as religiões. De todos os tratados de paz. Lua de mel: uma missão espacial e especial.

Americanizada, eu? Deus me live. Nas minhas enter(anhas), nunca, ok? Contra todos os dízimos. E contra os vendedores de fetiches. Só me interessa o que for dito por europeu. Lei do revisor (colonizado e colonizador).

O que atropela a verdade são os artigos científicos sem uma contextualização.

Segundo Darcy Ribeiro, "Eram todos filhos de ninguém. E dessa ninguendade nasceu um povo único sem precedentes no mundo".

Pretuguês exige ser conjugado só nos verbos intransitivos. Sem concessões, nem purugunta pru selo de alvura dos muy eruditos. Mas o cientista...! ah, esse só navega pelos transitivos! É crente do Norte. Reza todas as novenas da chibata.

Pelo aquilombamento da razão. Vissungo: "Purugunta onde vai, Oi parente, pru quilombo do Dumbá!"

Queremos a unificação de todas as revoltas eficazes na direção do (que é) homem: de 11 em 11 minutos, das periferias pretas às mansões limpas por pretas, todas as girls choram. E, não, não é TPM.

O futuro é ancestral. É por isso que o caule arranhado de uma árvore guarda algum futuro: mais vale ouvir o rum do que ler um ensaio antropológico sobre ele. Os ouvidos são de acesso livre, o paper, não.

Emicida em seu Mufete: "Dizem que o diabo veio nos barcos dos europeus. Desde então, o povo esqueceu que, entre os meus, todo mundo era Deus".

Um chá, uma reza e uma boa coça de arruda. Isso é tudo que temos para acompanhar a manifestação dos dotô pela TV.

Dica do Mandic: Se mentir seja breve.

Só podemos atender ao mundo pelas telas, a oralidade está voltando... 
Que as rezadeiras nos benzam. Que os padres e pastores batizem. Que os ateus não orem. Que as pessoas sejam livres. Crenças. Magia. Arrotem.

Contra o pagamento para divulgação de pesquisas científicas. Contra a meritocracia. O acadêmico, vítima da visão eurocêntrica, da língua inglesa e do esquecimento das conquistas anteriores.

Artigos. Artigos. Artigos. Artigos. Artigos. Artigos. Artigos.

Estamos gravando. Todos concordam?

Eu uso máscara. Tu usas máscara. Nós protegemos os coletivos.

Salve os brócolis. Abaixo o pum das vacas.

Nunca fomos catequizados. Fizemos foi o SOX. O sistema travestido de Cobra. Sendo Unix. Ou figurando nas óperas dos personal computers de bons sentimentos acadêmicos.

Tínhamos algo e perdemos os caminhos. A idade das trevas!

A magia e a vida mediadas por telas, por máscaras, por distanciamentos. Como transpor tantos filtros? Que novas gramáticas usar? Ai! que preguiça!...

Perguntei a um homem o que era a tese. Ele me respondeu que era a garantia de obter o doutorado. Comi-o.

Contra o marco temporal nos contos das Améfricas. Sem Colombo, sem Platão, sem Windows e sem orientação.

A ciência-que-conduz-necessariamente-ao-progresso é como os Correios.

Contra as sublimações antagônicas trazidas nas telas.

DEMO-cracia ou democra-CIA?

A farmacêutica e pesquisadora Nilsa Sumie Yamashita Wadt do Serviço Especializado em Lesões Vasculares e Neuropáticas (SELVEN), do Sistema Único de Saúde (SUS) de Valinhos (SP) concluiu em suas pesquisas que o uso do chá de folhas de goiaba e pitanga reduz em $45 \%$ o tempo de cicatrização de nossas feridas.

Nosso Shakespeare in love se escreve com queijo e goiabada. Nós temos Pitanguy, Rio Vermelho, Acarajé da Dinha e somos o lugar de encontro dos Tupinambás com Caramuru. Nossas feridas continuam abertas.

As migrações. A fuga de cérebros. Contra o corte de bolsas e o sucateamento das pesquisas. Contra o utilitarismo e o controle acadêmico pela racionalidade hegemônica do conhecimento. 
De Jones Manoel a Caio Coppolla. A transfiguração do tatu-bola-da-caatinga em modem 5G. Antropofagia.

O bater familiar e a humilhação oral. Vergonha. Tolerância surreal + falta de ação + o oprimido $+\mathrm{o}$ opressor.

Antes dos e-mails e grupos de Whatsapp, trabalhávamos menos horas por dia.

Comer é sempre um acontecimento. Não amole.

O Rio só é bonito visto de cima. Coisa de quem pode pegar um avião...

Contra a falta de memória. Por uma política renovada.

Somos virais. As ideias são likes e lacres. "Você foi cancelado!"

Mais vale um link certeiro que várias mídias hegemônicas voando.

Essa nação nunca foi fundada. Nem será (?). Somos peles (alvas e alvos), um twitter presidencial, algum osso e um nude frontal de compartilhamento culposo.

Aqui, no mundo dos aforismos, pseudônimos valem mais que muitos sobrenomes: Cunhambebinho, Odjuavu, Japi-Mirim, Freuderico, Jaboti, Braz Bexiga, Júlio Dante, Cabo Machado, Tamandaré, Pinto Calçudo, Poronominare, Guilherme da Torre de Marfim, Cunhambebe, Coroinha, Menelik (o morto sempre vivo), Marxilar, Piripipi, Tupinambá, Pão de Ló, Le Diderot, Jacó Pum-Pum, Seminarista Voador e outros.

O condor, pássaro símbolo da liberdade, precisa das duas asas para voar.

O antropófago Lewis Hamilton bateu todos os recordes, inclusive aqueles do Schumacher e do Senna na F1: é negro, inglês, corre por uma escuderia alemã que mais parece um outdoor da empresa estatal malaia Petronas que explora petróleo nos campos dos goytacazes, grandes antropófagos.

Em 22 de janeiro de 1922, em Cruzinha, Carazinho, nasceu um gurizinho que ficou sem nome por alguns anos. Ele seria um braço forte, uma pedra dura: Itagiba. Prenúncio antropófago.

Vegetarianismo é uma palavra indígena antiga que significa caçador ruim. "Carnívoro", por sua vez, é o mesmo que "consumidor de congelados" na língua tupi-euaqui.

A tinta que cai na pele do tempo é rebelde: a gravura se põe e amanhece ser.

Teclado mole e disciplina dura tanto batem até que a tese sai.

Onde há fumaça, há a cabeça de um pós-graduando pegando fogo.

Trabalhos passados movem moinhos. 
Cavalo preso também pasta. Não é preciso ir ao bar pra tomar sua cervejinha.

Cada macaco no seu galho, pois o macaco vizinho pode estar contaminado.

A indução leva à ação, mas a ação pode levar à morte.

Não sair pode ser a solução, mas alguém deixará de comer por causa disso.

Para dançar pela rota sem muros é preciso trair os pés marcados.

A mente é um monstro mítico feito no e para jorrar. Bicho-touro-estranho, pés dançantes, Dionísio errante.

Selvagem só é bom se for deglutido antes do café.

Água mole em pedra dura, tanto bate até que molha.

Em terra de cego, quem tem um olho é expulso.

Deus ajuda quem madruga, mas dormir não é pecado.

Afinal, quanto mais se f..., menos se pensa e melhor se dorme.

A irritação demonstra uma (ou mais) frustração.

Atender compreende entender.

Energias vibracionais se engolem.

Quem pede pouco, ganha menos ainda; nessa vida, ser pidão é sobreviver.

Diga com que autores tu andas que lhe direi quais são seus coletivos de pensamento. Comer tem vários sentidos.

Submissões. Submissões. Submissões. Submissões. Submissões. Submissões.

Estamos gravando. Todos concordam?

\section{Conclusões}

Em termos aforísticos, temos orgulho de conseguir expressar nossas ideias utópicas, sem lugar. Sendo assim, sobre tudo que escrevemos até aqui, caso ainda esteja em busca de conclusões recomendamos que, em vez de consultar Thomas More, Robinson Crusoé, Caramuru, Bispo Sardinha, Pero Vaz Caminha, Hans Staden e outros, nós sugerimos, virtualmente, consultar o Morubixaba Cunhambebe. Acreditamos que ele, cordialmente, lhe responderá algo como:

- "Sou uma onça. Não amole, é gostoso". 


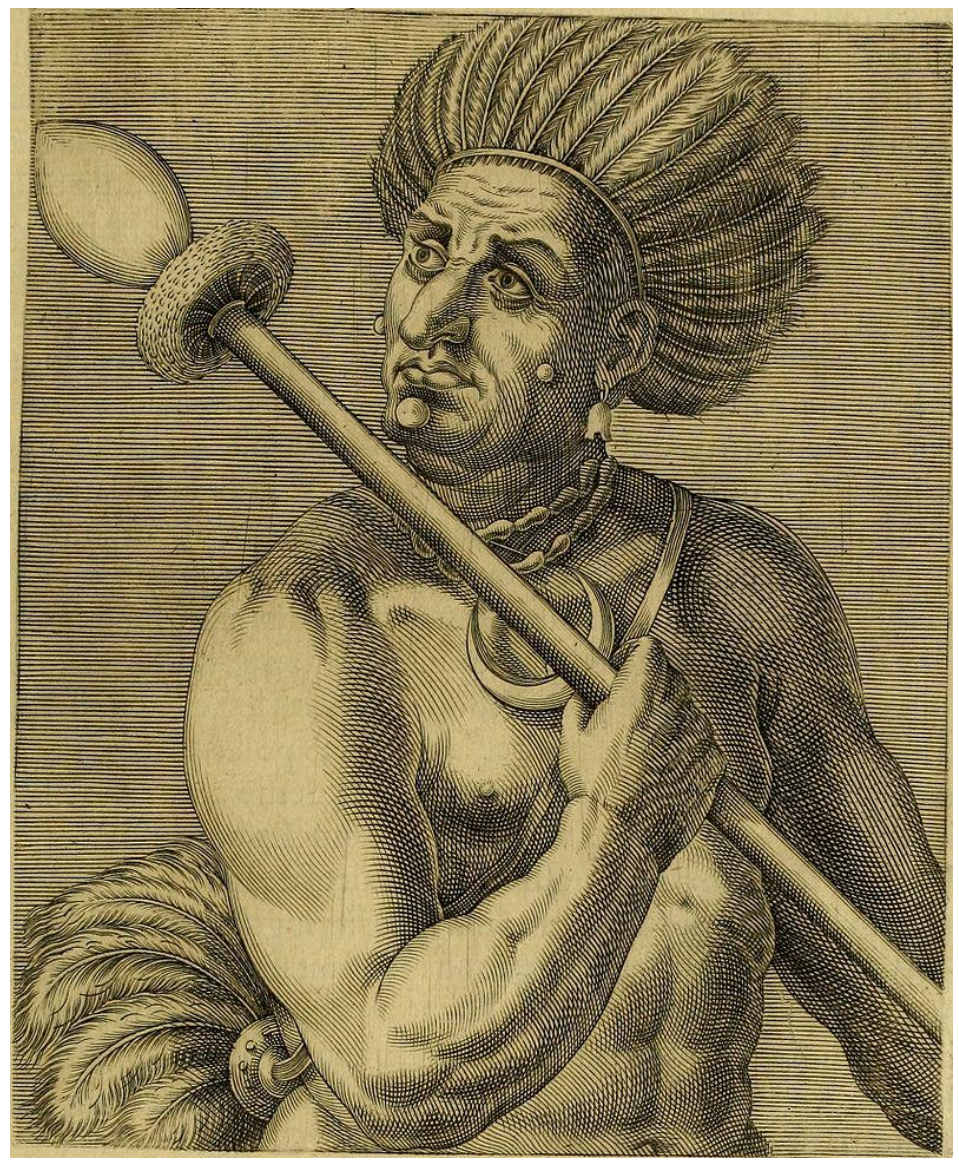

Figura 2. Cunhambebe, ilustrado por André Thevet, cosmógrafo francês que acompanhou a expedição de Nicolas Durand de Villegaignon.

Fonte: Wikimedia / Domínio Público. ${ }^{1}$

\section{Agradecimentos}

Agradecemos a todas as pessoas antropófagas e selvagens do planeta e além!

\section{Financiamento}

O presente trabalho foi realizado com apoio da Coordenação de Aperfeiçoamento de Pessoal de Nível Superior - Brasil (CAPES) - Código de Financiamento 001.

\section{Referências bibliográficas}

AMARAL, T. ANTROPOFAGIA. Óleo sobre tela, 79 x $101 \mathrm{~cm}$, Fundação José e Paulina Nemirovsky. Disponível em: http://tarsiladoamaral.com.br/base2016/wpcontent/uploads/2016/11/antropofagica-10.png. Acesso em 10 nov. 2020.

ANDRADE, M. Manifesto da Poesia Pau-Brasil. In: CASTRO ROCHA, João Cezar; RUFFINELLI, Jorge (Orgs.). Antropofagia hoje? Editora: É Realizações. p. 21-25. São Paulo. 2011.

${ }^{1}$ Disponível em: https://commons.wikimedia.org/wiki/File:Quoniambec.jpg. Acesso em: 14 nov. 2020. 
ANDRADE. M. R. M. Paulicéia Desvairada. São Paulo: Poeteiro Editor Digital, 2016.

ANDRADE, O. Manifesto Antropófago. In: Revista de Antropofagia, n. 1, mai. 1928. Hemeroteca Digital Brasileira da Biblioteca Nacional. Disponível em: http://memoria.bn.br/pdf/416410/per416410_1976_00001.pdf. Acesso em: 10 nov. 2020.

AZEVEDO, B. Antropofagia - palimpsesto selvagem. São Paulo: Editora Cosac Naify, 2016.

AZEVEDO, A. B. S. S. Antropofagia: palimpsesto selvagem. 2012. Dissertação (Mestrado em Literatura Comparada) - Faculdade de Filosofia, Letras e Ciências Humanas, Universidade de São Paulo, São Paulo, 2012. Disponível em: https://www.teses.usp.br/teses/disponiveis/8/8151/tde-04082016-165033/pt-br.php.

Acesso em: 15 nov. 2020.

CARUZO, M. A. Religião a partir da experiência originária da vida: proposta de Heidegger e sua crítica ao Sagrado de Otto. Sacrilegens, [S. 1.], v. 12, n. 2, 2015. Disponível em: https://periodicos.ufjf.br/index.php/sacrilegens/article/view/26836. Acesso em: 28 abr. 2021.

FREITAS, C. E. Entre compromissos e obrigações: um estudo das experiências morais das classes médias e populares no nordeste na perspectiva da nova sociologia da moralidade. Tese de doutorado defendida no CCHLA/UFPB. Orientação: Simone Magalhães Brito. 2018.

KRENAK, A. O amanhã não está à venda. Coletânea de entrevistas feitas por Bertha Maakaroun. Editora Expresso. Lisboa. 2020.

MORALES, L. E. Aforismos y otras mentiras. Polônia: Edición Simon Editor 2020.

NIETZSCHE, F. Assim Falava Zaratustra: um livro para todos e para ninguém. Título em alemão: Also sprach Zarathustra. Originalmente publicado em 1883. Versão para eBook disponível na URL: http://www.ebooksbrasil.org/adobeebook/zara.pdf. 2002.

NIETZSCHE, F. 100 Aforismos Sobre o Amor e a Morte (Coletânea feita por Paulo César de Souza). São Paulo: Penguin e Companhia das Letras, 2012.

NODARI, A. A única lei do mundo. In: CASTRO ROCHA, João Cezar; RUFFINELLI, Jorge (Orgs.). Antropofagia hoje? Editora: É Realizações. pp. 455-483. São Paulo. 2011

PAIVA, E. N. Antropofagias tecnocientíficas: devorando algumas ideias. Revista Scientiarum Historia, v. 1, p. 9-12 dez. 2019.

PINTO, Á. V. O conceito de Tecnologia. Editora Contraponto. Rio de Janeiro. 2005.

VIVEIROS DE CASTRO, E. A inconstância da alma selvagem - e outros ensaios de antropologia. Editora Cosac Naify. São Paulo. 2002. 
SHAPIN. S. Nunca Pura: Estudos Históricos de Ciência como se fora produzida por pessoas com corpos, situadas no tempo no espaço, na cultura e na sociedade, e que se empenham por credibilidade e autoridade. Tradução de Erick Ramalho do original NEVER PURE. Fino Traço Editora. Belo Horizonte. 2013.

SIMAS, L. A., RUFINO, L. Fogo no mato: as ciências encantadas das macumbas. Editora Mórula. Rio de Janeiro. 2018.

STEGMAIER, W. Nietzsche como destino da filosofia e da humanidade? Interpretação contextual do $\S 1$ do capítulo "Por que sou um destino", de Ecce Homo. Tradução de João Paulo Simões Vilas Bôas. Trans/Form/Ação, Marília, v.33, n. 2, p. 241-278, 2010. 